\title{
Lung function parameters and MVOC
}

\author{
U. E. Rolle-Kampczyk ${ }^{1}$, M. L. Greef ${ }^{1}$, O. Manuwald ${ }^{3}$,
} M. Rehwagen ${ }^{1}$, O. Herbarth ${ }^{2}$, S. W. Röder ${ }^{1} \&$ A. Müller ${ }^{1}$

${ }^{I}$ Department of Human Exposure Research and Epidemiology, Centre for Environmental Research Leipzig-Halle, Leipzig, Germany, ${ }^{2}$ Department of Environmental, Medicine and Environmental Hygiene, Faculty of Medicine, University of Leipzig, Leipzig, Germany

${ }^{3}$ Institute of Environmental Medicine, Erfurt, Germany

\section{Abstract}

The aim of this research was to analyse whether there are associations between lung function parameters and living in mould exposed conditions. Domestic exposure to mould is a common problem nowadays. It is known that mould burden can provoke allergies and unspecific disorders. The role of constituent parts of mould, and in particular of microbial volatile compounds (MVOC), on health is currently partially unclear.

124 persons from the city of Erfurt, Germany (some of whom have been exposed to mould) were investigated within a special consultation-hour with focus on environmental medicine.

Simultaneously home visits were carried out. During these visits dust and air samples were collected for further analysis. Among other items, the indoor air concentrations of MVOC as metabolites of mould were determined. The medical checkup included in-depth anamnesis and clinical investigation completed by a detailed lung function test. MVOC data are based on GC-MS measurements of total amounts of 2-Methylfurane, 3-Methylfurane, 2-Methyl-1-Propanol, 2-Pentanol, 3-Methyl-1-Butanol, Dimethyldisulfide, 2-Hexanone, 1-Octene, 2-Heptanone, 2-Octanone, 3-Octanol, Fenchone, $\alpha$-Terpineol and Thujopsene.

It was found that the burden with mould and the burden with MVOC in accommodation is positively associated with changes in lung function parameters. Different lung function parameters were influenced depending on points of view. Generally, more parameters were influenced by looking for associations with mould and the effects found are stronger. An increase of residual volume could be obtained for mould $(\mathrm{p}=0.001, \mathrm{n}=84)$ and for MVOC $(\mathrm{p}=0.04, \mathrm{n}=76)$. Furthermore, an OR (95\% confidence interval): 3.01 (1.03-9.05) could be found for mould and for MVOC: OR (95\% confidence interval): 1.07 (1.01-1.15), both adjusted for daily smoking, general smoking in accommodation, medication against allergies and pulmonary infects during the last four weeks

It can be concluded that MVOC are able to contribute to negative health effects caused by mould.

Although the described effects appear to be low, it should be taken into account that ORs given for $\Sigma$ MVOC are per change of $1 \mu \mathrm{g} / \mathrm{m}^{3}$. Therefore an increase of $10 \mu \mathrm{g} / \mathrm{m}^{3}$ leads to an OR of $1.110=2.59$.

Keywords: domestic mould, MVOC, lung function. 


\section{Introduction}

Indoor air quality has developed more importance because most people in developed countries spend their time indoors. Moulds are ubiquitous and grow almost anywhere indoors and outdoors. Since the rate of mouldy apartments is increasing due to updates concerning energy, construction defects, thermal bridges and ventilating failure, a particular interest has developed on health outcomes caused by indoor mould. Results of many studies have demonstrated that mould and their metabolites can contribute to adverse health effects such as disturbances in the airway system (e.g. asthma), allergies and unspecific symptoms [1-3]. Fungi have an allergic potential (via allergens in spores), can cause toxic or immune modulatory effects (effects of mycotoxins) and can act as irritants via MVOC. A further biological active compound is the ingredient of cell membrane (1,3)- $\beta$-D-glucan [4]. Mycotoxins and MVOC are counted among so called secondary metabolites of mould. This means that the compounds are not indispensable to life and are synthesised outside of primary metabolism such as during periods of growth. MVOC have low odour thresholds. In some cases the mouldy odour is the first indicator for mould. Most people feel the odour is unpleasant. The contribution of MVOC on health effects is different as discussed in the literature. Controlled human exposure studies (chamber experiments) have shown acute effects of VOC/MVOC on eyes, different mucosa membranes, attention and headaches etc. [5,7]. Walinder et al. have shown effects on an increasing blinking frequency of the eyes, higher concentrations of myeloperoxidase and lysozyme in bronchoalveolar lavage, as well as a decreasing forced vital capacity in chamber experiments with the MVOC 3Methylfuran up to a concentration of $1 \mathrm{mg} / \mathrm{m}^{3}$ [6]. These concentrations are higher than those found in real life. Therefore some authors share the opinion that the indoor concentrations of MVOC are too low to generate health effects. For this reason one aim of our investigations was to verify whether it is possible to see effects caused by MVOC under real life conditions.

\section{Methods}

124 persons with mould exposure (17 children under 18 years and 106 adults) from the City of Erfurt, Germany were investigated within a special consultation-hour with the focus on environmental medicine. These investigations were embedded in an intervention study with the aim of clarifying both whether mould caused health effects in detail and the influence of the renovation of apartments on human health. All participants completed a questionnaire containing questions on accommodation, life style and health. Simultaneously home visits were carried out. During these visits dust and air samples were collected for further analysis. Among other things indoor air concentrations of MVOC as metabolites of mould were determined. The medical check up has included in-depth anamnesis and the clinical investigation was completed by a detailed lung function test. 
The following lung function parameters were tested by body plethysmography: forced expiratory volume during one second (FEV(1)), forced vital capacity (FVC), residual volume (RV), peak expiratory flow (PEF), maximum expiratory flow $(\operatorname{MEF}(25-75 \%))$ and total lung capacity (TLC). Lung function parameters examined by impulse oscillometry are: pulmonary resistance $(\mathrm{R})$, reactance $(\mathrm{X})$ as well as dynamic compliance $(\mathrm{C})$.

MVOC samples were collected passively using 3M monitors and actively using tenax tubes. MVOC analysis were realised by GC-MS. The results shown in this paper were calculated using measurements from passive sampling. Recommendations on the selection of MVOC are given in [8].

Statistical analyses were performed applying the work package Statistica for Windows (version 7, Statsoft Inc., Tulsa OK, USA). Crude and adjusted odds ratios (OR) were calculated based on the Maximum Likelihood method with a $95 \%$ confidence interval $(95 \% \mathrm{CI})$. The investigated persons were patients of the special consultation-hour on environmental medicine in the city of Erfurt. Confidentiality of the data was observed at all times.

\section{Results}

The analysed concentrations of MVOC were low on average. The mean concentrations, detection limits as well as ranges are presented in Table 1.

Table 1: $\quad$ Detailed information about MVOC concentration $\left[\mu \mathrm{g} / \mathrm{m}^{3}\right]$.

\begin{tabular}{|l|l|l|l|l|}
\hline MVOC & $\begin{array}{l}\text { limit of } \\
\text { detection } \\
(\mathrm{LOD}) \\
{\left[\mu \mathrm{g} / \mathrm{m}^{3}\right]}\end{array}$ & $\begin{array}{l}\text { mean } \\
{\left[\mu \mathrm{g} / \mathrm{m}^{3}\right]}\end{array}$ & $\begin{array}{l}\min \\
{\left[\mu \mathrm{g} / \mathrm{m}^{3}\right]}\end{array}$ & $\begin{array}{l}\max \\
{\left[\mu \mathrm{g} / \mathrm{m}^{3}\right]}\end{array}$ \\
\hline 2-Methylfurane & 0.038 & 0.95 & $<$ LOD & 15.11 \\
\hline 3-Methylfurane & 0.039 & 0.24 & $<$ LOD & 2.53 \\
\hline $\begin{array}{l}\text { 2-Methyl-1- } \\
\text { Propanol }\end{array}$ & 0.044 & 2.43 & $<$ LOD & 21.34 \\
\hline 2-Pentanol & 0.016 & 0.25 & $<$ LOD & 5.79 \\
\hline $\begin{array}{l}\text { 3-Methyl-1- } \\
\text { Butanol }\end{array}$ & 0.047 & 0.90 & $<$ LOD & 23.42 \\
\hline Dimethyldisulfide & 0.026 & 0.03 & $<$ LOD & 0.23 \\
\hline 2-Hexanone & 0.032 & 0.28 & $<$ LOD & 1.28 \\
\hline 1-Octene & 0.068 & 0.38 & $<$ LOD & 4.35 \\
\hline 2-Heptanone & 0.019 & 1.30 & 0.08 & 12.08 \\
\hline 2-Octanone & 0.039 & 0.49 & $<$ LOD & 2.96 \\
\hline 3-Octanol & 0.097 & 0.09 & $<$ LOD & 1.760 \\
\hline Fenchone & 0.054 & 0.078 & $<$ LOD & 1.39 \\
\hline$\alpha$-Terpineol & 0.419 & 0.59 & $<$ LOD & 10.64 \\
\hline Thujopsene & 0.442 & 0.12 & $<$ LOD & 2.88 \\
\hline$\sum$ of all MVOC & & 8.21 & 0.54 & 71.31 \\
\hline
\end{tabular}


We were able to show that the question of burden mould and the question of burden with MVOC in accommodation is associated with a pathological influence on lung function parameters. It could be found that the positive answered question "is there visible mould in your apartment?" was connected to lung function parameters using the logistic regression model as follows:

- $\quad$ Peak expiratory flow (PEF) and forced vital capacity (FVC), were both pathologically decreased;

- $\quad$ Residual volume (RV) pathologically increased.

Elevated values for MVOC measurements were connected to

- Maximum expiratory flow 25\% $\operatorname{MEF}(25)$ and peak expiratory flow (PEF), both were pathologically decreased;

- $\quad$ Total lung capacity pathological (TLC) and residual volume (RV), both were pathologically increased.

Different lung function parameters were influenced depending on the point of view. Generally, more parameters were influenced by looking for associations to mould and the effects found are stronger. An increase of residual volume could be obtained for mould $(p=0.001, n=84)$ and for MVOC $(p=0.04, n=76)$. Furthermore, an OR (95\% confidence interval): 3.01 (1.03-9.05) could be found for mould and for MVOC: OR (95\% confidence interval): 1.07 (1.01-1.15), both were adjusted for daily smoking, general smoking in accommodation, medication against allergies and pulmonary infections during the last four weeks.

\section{Discussion/conclusion}

Our results concerning mould did show better results than the results concerning MVOC.

A probable reason may be that MVOC concentrations were low. Furthermore, MVOC influences the body on an irritative path. A general burden with visible mould can affect the human body via the toxic, allergic and irritant paths. Last but not least, MVOC have very low odour thresholds and so it seems there is an additional psychological path.

It can also be concluded that MVOC are able to contribute to negative health effects caused by mould.

Although the described effects appear to be low, it should be taken into account that ORs given for $\Sigma$ MVOC are per concentration change of $1 \mu \mathrm{g} / \mathrm{m}^{3}$. Therefore an increase of $10 \mu \mathrm{g} / \mathrm{m}^{3}$ leads to an OR of $1.1^{10}=2.59$.

\section{References}

[1] Peat, J. K., Dickerson J. \& Li, J., Effects of damp and. mould in the home on respiratory health: a review on literature. Allergy 53, pp. 120-128, 1998.

[2] Garrett, N. H., Indoor airborne fungal spores, house dampness and associations with environmental factors on respiratory health in children. Clin Exp Allergy 28, pp. 459-467, 1998. 
[3] Fisk, W. J., Lei-Gomez, Q. \& Mendell, M. J.: Meta-analyses of the associations of respiratory health effects with dampness and mould in homes. Indoor Air 14, pp. 284-296, 2007.

[4] Rylander, R. \& Lin, R., (1,3)-ß-D-glucan-relationship to indoor air-related symptoms, allergy and asthma. Toxicology 1552, pp. 47-52, 2000.

[5] Korpi, A., Kasanen, J.P. \& Alarie, Y. et al.: Sensory irritating potency of some microbial volatile organic compounds (MVOCs) and a mixture of five MVOCs. Arch Environ Health 54, pp. 347-352, 1999.

[6] Walinder, R., Ernstgard, L. \& Johannsen, G. et al., Acute Effects of a Fungal Volatile Compound. Environ Health Perspect 13, pp. 1775-1778, 2005.

[7] Molhave, L., Jensen, J. \& Larsen, S., Subjective reactions to volatile organic compounds. Atmos Environ 25 (A), pp. 1238-1293, 1991.

[8] Müller, A., Rehwagen, M. \& Weißenborn, T. et al., Expositionsuntersuchungen von Schadstoffen im Innenraum LEIPIUntersuchungsprogramm - eine Interventionsstudie, Partikuläre und molekulare Belastungen der Innenraum- und Außenluft, Scientific series University Lübeck, Institute of Microbiology and Hygiene, ed. R. Keller et al. 10, pp. 283-302, 2006. 